\section{Climital Alecture}

ox

\section{E N E S C T I O N.}

By

W. O. MARKHA M, M.D., PIIYSICI

Gentrenen,-I have to-day to bring under your notice two cases which, as I think, illustrate in a striking way the beneficial effects of venesection. In both cases, the patients were suffering, and suffering severely, from lung-diseases; and in both the symptoms for which the venesection was practised were those which represent in a marked degree interference with the free play of the heart and lungs. I will, in a few words, relate the history of these cases; and then make a few remarks touching the operation of the venesection in their cure.

J. J., aged 36, a healthy man, was seized, about a week before his admission into St. Mary's IIospital, with difficulty of breathing and "stitch" in the right side. These symptoms increased up to the time when he entered the hospital. When I saw him, the morning after his admission, he was sitting up in bed, fighting for breath, and, as he expressed it, felt almost suffocated. His pulse was rapid; his tongue moist and coated; and his face livid. He had been delirous during the night. An examination of his chest, hastily made, showed us that he was the subject of double pleuropneumonia, and that there was complete dulness on percussion before and behind over at least three-fourths of the right lung. Now, if ever one might have ventured to predict, from a consideration of symptoms and physical signs in such a case, that the patient was being surely and rapidly asphyxiated; and that, unless some immediate and great relief were quickly given him, he would inevitably perish, assuredly one might have done so in this case. Guided by this impression, and considering that the man had only been ill a week, and had previously enjoyed good health, I ordered him to be bled at once, and freely bled-i.e., until he showed signs of relief or fainting. I may here remark, as a curious sign of the times we live in-of the revolutions which periodically occur in medicine, as well as in all other things-that the house-surgeon had never bled a patient, nor had seen a lancet used in bleeding! About sixteen ounces of blood were taken from the man's arm, to his very great and immediate relief. The pain in the right side (where the pleuritic symptoms were most acute) returned again in the evening, and therefore some eight to ten leeches were then applied. Next morning, the man was, comparatively speaking, in a most comfortable state. He no longer suffered from those urgent, and, as I deemed them, fatal signs of distressed breathing, which afflicted him the day before.

And what had brought all this so great relief to him, if not the venescetion? Surely, if in any case we may draw conclusions that the relief given in disease was the result of the remedy administered, we may do so in such a case as this, where the nature of the disease is so manifest, where the relief following the remedy is so undoubted, and where it follows so immediately upon its use. More than this: it may be asked, Is there any other remedy besides venesection which could in such a case have produced relief so great, and so immediate? Well, then, unless we choose to shut our eyes to as palpable a fact as any which can be produced in the matter of the action of therapeutical agents, it seems to me that we are driven to the conclusion that venesection is, in such a cise, the most sovereign and life-saving of remedies; that, in the instance before us, it had rescued the man from impending death. I do not intend to follow out the history of this man's case through his long convalescence. I will only add that, in addition to the double pleuropneumonia, he was afterwards attacked with pericarditis; and that subsequently a pleuritic abscess of the right side opened into, and discharged its contents through, the lungs and the trachea. Notwithstanding all this long catalogue of serious affections, he eventually left the hospital convalescent.

The other patient, alluded to as illustrative of the beneficial uses of venesection, was an adult man, who had occasionally suffered from "asthmatic" symp. toms. When he entered the hospital, he breathed with much difficulty, and, in fact, suffered " excrneiating" pain in the left side. His respirations were 50 in a minute, and his pulse very rapid. His disease was pneumonia of the left side. He was immediately bled to about fifteen ounces, and was as immediately relieved of his great distress. I will only add of him, that he thereafter rapidly and satisfactorily recovered from the attack, and left the hospital cured.

Now, I call your attention to these two cases, because they seem to me, as far as they go at least, to show the error of the present "extreme in practice", which virtually abolishes venesection from our list of therapeutical agents. I believe that in one of these cases, at all events, the man would inevitably have perished, had he not been bled.

You know the modern theory about bleeding, or rather I should call it the present prevailing theory ; for it is in no way modern. It is this: that discasea have changed their type; and that men of these days will, therefore, not bear bleeding as men did thirty or forty years ago. I have elsewhere shown,* and, as I think, shown demonstratively, that this theory is a mere scapegoat which men have made use of as an apology for their own apparently inconsequent conduct-in order, in fact, to explain how it is that they no longer employ venesection as they once employed it in other and darker ages of mellicine. I have asked and sought for the proof of the assertion that men will not bear bleeding now as they did in those other days; and I find it utterly wanting. I find that the assertion is founded on some indefinite kind of belief-on ordinary medical belief-in fact, on mere surmise and opinion. If you ask men for anything like a reasonable proof of the opinion, you ask in vain. I showed, in the lectures referred to, that this idea of an incapacity of man tc bear bleeding was flourishing upwards of a hundred years ago-has, indeed, flourished at intervals during all ages, and has been handed down from physician to physician through generations past. A hundrei years ago, Hunter tells us that some of the physi. cians of his day discovered, just as physicians of our own day have done, that diseases would not beal bleeding as well as they did formerly. Medicine i:

* See Gulstonian Lectures, Bhitish Medical Journal, Apri

$9,16,23,30$, and May 7,1864 . 
continually repeating its own errors. At this moment, however, I only ask you to keep these two cases-surely I may call them these two facts-in your eye, when you may be tempted at some future day, and in an urgent case, and contrary to your own judgment, to forego venesection solely because you have a dread of this bugbear of a change of type in disease-of some modern incapacity of human nature to bear loss of blood. Just reflect again on what you here see going on around you daily and hourly in this matter of loss of blood. Look at patients, after accidents, lying in our surgical wards blanched through loss of blood. Note the enormous quantity which often wells away from women during labour ; measure the black vomitings of patients suffering from ulceration of the stomach, and the bloody sputa sometimes thrown up in tubercular disease of the lungs; note the large dejections of blood which often accompany ulceration of Peyer's glands in typhoid fever : note all these, and many other sources of often most copious hæmorrhages which you see going on daily under your eyes in the hospital; and note also that the patients recover, and recover rapidly, from the effects of such large hæmorrhages. Mark how little they exhibit of that incapacity to bear loss of blood which they ought to exhibit if there were any truth in the theory that we are now living in an asthenic phase of diseases. More than this: I might ask you to observe the very great relief which these spontaneous hæmorrhages often bring with them, especially in those cases of disease in which the lungs and the heart are concerned.

Well, gentlemen, if you will note all these facts, and then carefully reflect upon them, you will, I am sure, at all events, have your belief greatly shaken in the truth of the idea that to take a few ounces of blood from a man by the lancet is something akin to taking the very life out of his body. These reflections will shake your confidence in the truth of the theory upon which is based the modern practice of non-bleeding in disease. And then, if you will also call to mind the markedly beneficial effects following the bleeding, and noted by your own eyes, in the two cases here spoken of, you may probably be induced, on proper and fitting occasions, not to fear to resort to this most excellent of remedies. This is the lesson which 1 have wished to impress upon you to-day.

And one word more, let me say, as to the probable action of the venesection in cases of this kind. The idea generally entertained on this point is, I believe, quite erroneous, and, what is worse, an error, which prevents the use of the remedy. It is thought that venesection is of service in inflammatory diseases, through the beneficial influence which it exercises over the local inflammatory process. I believe there is no proof whatever that venesection has any directly beneficial influence over any inflammatory process.

If venesection be of service in internal, it should equally be of service in external inflammations-i.e., in those inflammations whose progress we can see with our eyes. But in what records of "bleeding" times, will you find any satisfactory proof that it ever was of service in such inflammations? And where will you find an authority of the present day to tell you that he has seen the benefits of venesection in external inflammations?

The truth is that, in past days, when venesection was in its glory-I mean gloriously abused-you will ever find that its benefits were most loudly pro- claimed in those internal inflammations in which the action of the lungs or heart was impeded; and, assuredly, at the present day, there is never any pretence or thought of bleeding a man, except in those diseases in which the respiratory or circulatory organs are directly or indirectly affected. Facts like these, and other facts which I have not time now to tell of, indicate $i$ priori the correctness of the proposition $I$ here make to you; viz., that venesection has no directly beneficial influence over the inflammatory process itself ; but that it is of benefit, by removing some of the accidents which arise secondarily out of those inflammations and diseases-viz., the impediments to the free play of the lungs and heart. No one ever did, or ever does, think of bleeding in pneumonia, unless the pneumonia be so extensive as to seriously interfere with the play of the heart and lungs. Men always did, and always do, judge of the necessity for the venesection by the amount of impediment to the action of those organs displayed in the physical signs and symptoms which indicate the impediment and the nature of it. The benefits of the bleeding, as I see the thing, are not the result of any good effected by it at the seat of the inflammation-of any good directly effected by it over the inflammatory process. Its benefits are rather to bo ascribed to the freedom of action-the relief given by it to the play of the other, the uninflamed parts of the lungs and the engorged heart-of the organs or parts in fact which have become secondarily engorged, i.e., impeded in action, in consequence of the inflammation. The bleeding neither arrests nor' alters directly the condition of the inflammatory process. ${ }^{*}$ It neither cuts the inflammation short, nor can it remove the exudations which are the necessary attendants of inflammation. In what possible way can bleeding alter directly the condition of a consolidated portion of lung? In the case of J. J., the bleeding most assuredly effected no instant change in the state of the inflamed parts of the lungs and pleura. But nevertheless the relief given by it was immediate-came whilst the blood was flowing from his arm-as it probably always comes, if the bleeding be of any service at all. Also, remark that the relief here given is just of the same kind as that which is given in cases, for example, of chronic diseases of the heart and of thoracic aneurism; in cases where impediments to the action of the heart and lungs, or, in other words, congestion of the heart and lungs, have suddenly arisen, and where inflammation does not exist. Hence, therefore, when bleeding is of service in the course of inflammatory diseases, it is so, not because it directly alters the inflammatory process, but because it relieves certain of the accidents which arise incidentally out of the inflammatory process-i.e., the congestion of the heart and lungs. Bleeding therefore, it may be said as a corollary of this, is of service only in those inflammations and diseases in the course of or out of which arise impediments to the play of the heart and lungs.

But, after all, let no theoretical arguing draw us away from the patent fact which we have seen with our eyes. We saw a man, to all appearance in extremis, fighting an unequal battle with disease. We found him to be the subject of double pleuropneumonia. We saw an immediate stop, then and there,

* Of course, excepting in so far as by modifying the general state of the system, it may modify the general forces wbich are concerned in or preside orer the process. 
put to the violence of this deadly struggle by bleeding. We saw the man recover from the moment of the bleeding. You may have heard him declare that the bleeding was the saving of his life-though you need not perhaps take any great account of a patient's opinion on such a point. You have seen all this. Well, gentlemen, I trust I have a sufficient sense of the fearful amount of fallacies which beset our medical reasoning-of what Dr. Barclay calls our "medical errors" - I believe I have a sufficient dread of the proverbially reigning confusion in our ideas of the post hoc and the propter hoc in matters therapeutical. But I think a man must be sceptical indeed, beyond all bounds of reason and common sense (if we may invoke that sense here), who refuses to connect effect with causation, the consequence with the antecedent, the cure of the disease with the venesection, in the cases $I$ have to-day brought under your notice. And this one other word let me add suggestively, What other remedy do you know of under the sun which is capable of proclucing off-hand, then and there, such great results in such formidable disease?

\section{OBriginal Commurnitations.}

\section{ON VITAL FORCES.}

By James Rhodes, Esq., Glossop.

Wrтночт much preface, I intend to state my views upon the question of the origin of the motor or vital force in the living organism.

I am not aware that any more appropriate term can be given to designate this subject than physicovital dynamics.

It is no less true for the human system than for the external universe, that no force can be lost or destroyed, and that no force can increase in any degree that which exists. When a force or power of motion has once ceased to act in one particular manner-as vis viva, or mechanical force, light, heat, or electricity-it bocomes transformed into some of the other forms of force, according to the relation which the surrounding parts possess in influencing the conversion. A good instance of this fact is mentioned by Professor Grove, in his work on the Correlation of Physical Forces (page 58).

I shall attempt to trace out the changes or conversion of forces which take place in the human system.

Without doubt, the prime moving force in all Nature is that which started worlds into existence-a First Cause, producing the law of gravitation in the heavenly bodies, and called by Mayer, Tyndall, and others, vis viva. Now, when this vis viva becomes arrested, an equivalent proportion of heat is produced and the disoovery of its equivalent may hereafter give us a key whereby we may estimate the value of any of the chemical agencies acting in the human economy.

The mechanical equivalent of heat is equal to 772 foot-pounds for $1^{\circ} \mathrm{Fahr}$, and was discovered by Mayer, a German of our profession, and by Joule of Manchester, whose labours were carried on independently and without the. knowledge of each other.

The leading philosophers now consider that one main force now exists. It is not my intention to dispute this important point, but it will be necessary to coincide with them. Yet the most uninitiated can ask, How can there be variety of forms out of one force? According to the more advanced philosophers, there exists a grand central force, round which systems of worlds revolve; and the light which emanates from the central bodies or suns of these systems is created by the very force which causes the revolution of the earth round our sun. It is not necessary here to enter fully into the subject of forces as they exist in external Nature, but the same laws apply to them in the human being; and I shall simply state the order and relationship which they possess to each other.

A gravitative force is established by the Great Unknown, which force is called vis viva. It is now discovered that a body falling to the earth will produce a certain equivalent of heat by the gravitative or moving force, which by this means becomes arrested and changed.

The following is an outline of the order in which I propose to consider this subject.

1. A close relationship exists between chemical force and the force of gravitation; and, under certain conditions, each of these produces heat and electricity-the former, the voltaic form; and the latter, frictional electricity.

2. A correlation between heat, light, and electricity is found to exist in the world around us ; and it remains to be shown how these are connected and related in the living body.

3 . It is not too much to expect that, as science advances, the total value of all these may be ascertained. The voluntary principle of man cannot create more force than is produced by the changes effected by the oxidising or chemical process in the system; otherwise exhaustion would be unknown, and sleep would be dispensed with.

4. There is the same correlation of forces in the human body, and these take their origin from simple motion, or vis viva; the attractive force existing in carbon, hydrogen, oxygen, phosphorus, etc., becoming converted into heat and nerve-force. These two are correlated, just as are heat and electricity. I do not consider that electricity and nerve-force present exactly the same phenomena; yet they are closely related, and almost identical.

5. I hope to show that heat and nerve-force are produced from the same origin; and that heat is not essentially, if at all, converted into nerve-force, as stated by Dr. Richardson; but that they are distinct at their origin, and that the nerve-centres are supplied with their force through afferent nerves-i.e., cerebro-spinal and sympathetic-as well as that generated within the brain itself. This nerve-force becomes expended, as in walking, through the motor nerves, and it is, a priori, likely to be conveyed along the afferent nerves just in the same amount; but, without a knowledge of these facts, it would be difficult to understand how or why.

I think the results of the following experiments sufficiently prove the origin of nerve-force.

Most of the readers of the Journal are conversant with the experiments of M. C. Bernard upon the sympathetic nerves, whereby he made known the facts of their " calorific and vascular" influence. When a branch of the sympathetic nerve is divided, the vessels are paralysed, and no longer oppose active resistance to the pressure of the blood; they become expanded, from loss of the contractile power of the capillaries, and a suspension of nerve-current to and from the capillaries.

The fact of an exaltation of temperature to $6^{\circ}$ or $8^{\circ}$ cent. indicates that what is lost in the non-production of nerve-force is converted into heat, or the plus heat is equal to the minus nerve-force lost, as shown by the loss of contractile force of the capillaries of 